\title{
SCreening for Controlled Substance Abuse in an Interventional Pain Management Setting: Evaluation of an Assessment Tool
}

$\overline{\text { Laxmaiah Manchikanti, MD, Vijay Singh, MD, Kim S. Damron, RN, Carla D. Beyer, RN, BSN, and Vidyasagar Pampati, MSc }}$

There is a need for an assessment tool to identify drug abuse behaviors in patients in pain treatment practices. Many assessment tools are complex, lengthy, lack external validation, and/or are difficult to administer. This prospective evaluation was undertaken to provide external validation for an assessment tool with 12 sections and 27 items. The test was applied in a prospective fashion to 500 consecutive patients: 100 patients in a drug abuse group and 400 patients in a non-abuse group. Drug abuse was defined as the misuse of controlled substances in a clinical set-

An important issue in interventional pain medicine is the non-medical use of prescription drugs by patients. This form of drug abuse exceeds that of all illicit substances except for marijuana and hashish (1-4). The 2001 National Household Survey on Drug Abuse (NHSDA) (5, 6) found statistically significant increases between 2000 and 2001 in the non-medical use of pain relievers $(1.2 \%$ to $1.6 \%)$ and tranquilizers $(0.4 \%$ to $0.6 \%)$, including the use of OxyContin ${ }^{\circledR}$ for non-medical purposes. While the true extent of prescription drug abuse is unknown, in 2001, 36 million Americans (16\% of persons age 12 or older) had used prescriptiontype drugs non-medically at least once in their lifetime. Although the most common category of prescription-type drugs used non-medically is pain relievers, other controlled substances are also used in significant numbers. Further, adolescents and young adults who used prescriptiontype drugs non-medically in the past year had a higher rate of other illicit drug use in the previous year.

From Pain Management Center of Paducah, Paducah, Kentucky. Address Correspondence: Laxmaiah Manchikanti, MD, 2831 Lone Oak Road, Paducah, Kentucky-42003, E-mail: drm@apex.net Funding: There was no external funding in preparation of this manuscript. ting, including obtaining controlled substances from other physicians or other identifiable sources, dose escalation with inappropriate use, and/or violation of controlled substance agreements. This study was performed in an interventional pain management setting with patients who were in stable therapy and were followed for at least one year.

Results identified 8 of 12 parameters to be useful in identifying patients with drug abuse. Three factors were particularly useful, allowing correct identification of patients with abuse behavior in $90 \%$ of cases (odds ratios greater than 100 and $P$ values of 0.001 or less). Important factors identified included excessive opiate needs, deception or lying to obtain controlled substances, and current or prior intentional doctor shopping. Together, these factors appear to identify $90 \%$ of patients with drug abuse. This tool provides a simple ,reliable, and cost effective means of screening for drug abuse during the clinical evaluation of patients in interventional pain management settings.

Keywords: Controlled substances, substance abuse, substance dependence, substance abuse assessment, assessment tool
The principle drug of abuse for nearly $10 \%$ of US patients is a prescription drug (4). This is further complicated by the frequent abuse of alcohol and illicit drugs $(3,7)$. Commonly abused drugs include opioids, benzodiazepines, sedative-hypnotics, and central nervous stimulants. It has been reported that approximately $77 \%$ of suicides involve benzodiazepines (8). Fishbain et al (9), studying drug abuse and dependency in chronic pain patients, concluded that between $3.2 \%$ and $18.9 \%$ of patients have been diagnosed with a substance abuse disorder. Manchikanti et al $(10,11)$ showed that the prevalence of controlled substance abuse in interventional pain management practice settings is $18 \%$ to $24 \%$. Manchikanti et al $(12,13)$ identified illicit drug use in $14 \%$ to $16 \%$ of patients without controlled substance abuse, and $34 \%$ of patients with controlled substance abuse. Polatin et al (13) identified substance abuse in $19 \%$ of patients with chronic low back pain. Chabal et al (14) showed that $28 \%$ of the patients met three or more drug abuse criteria. Other studies have identified similar rates of drug abuse in pain patients (10-27). Misuse of prescription controlled substances may lead to serious health consequences, including drug dependence, overdose, and death (26).
Thus, a challenging task faced by interventional pain specialists and other physicians managing chronic pain is determining whether or not a particular patient with chronic pain is abusing controlled substances. Several authors have emphasized the need to identify predictors of aberrant drug-related behavior and addiction in patients being treated with controlled substances for pain (14, 16, 28-34). Generally, in interventional pain management, controlled substances are not relied on as the sole management or mainstay of treatment. Rather, controlled substances are used as an adjunctive to interventional techniques, along with other modalities including physical therapy, psychological interventions, and non-opiate analgesics.

Terms used in describing abuse are confusing. Sees and Clark (32) illustrated how patients maintained on opioids for the treatment of chronic non-malignant pain could meet DSM-III-R criteria for substance dependence without actually being addicted. These criteria continue to be heavily weighted toward the presence of physical dependence and tolerance (9). Fishbain et al (9) showed that DSM-III-R criteria make no distinction between dependency and legitimate long-term medical use of opioids. Further, the diagnos- 
Table 1. DSM-IV diagnostic criteria for substance dependence

A maladaptive pattern of substance use, leading to clinically significant impairment or distress, as manifested by three (or more) of the following, occurring at any time in the same 12-month period:

\section{(1) tolerance, as defined by either of the following:}

(a) a need for markedly increased amounts of the substance to achieve intoxication or desired effect

(b) markedly diminished effect with continued use of the same amount of the substance

(2) withdrawal, as manifested by either of the following:

(a) the characteristic withdrawal syndrome for the substance

(b) the same (or a closely related) substance is taken to relieve or avoid withdrawal symptoms

(3) the substance is often taken in larger amounts over a longer period than was intended

(4) there is a persistent desire or unsuccessful efforts to cut down or control substance use

(5)a great deal of time is spent in activities necessary to obtain the substance (e.g., visiting multiple doctors or driving long distances), use the substance (e.g., chain-smoking), or recover from its effects

(6) important social, occupational, or recreational activities are given up or reduced because of substance use

(7) the substance use is continued despite knowledge of having a persistent or recurrent physical or psychological problem that is likely to have been caused or exacerbated by the substance (e.g., current cocaine use despite recognition of cocaine-induced depression, or continued drinking despite recognition that an ulcer was made worse by alcohol consumption

Adapted from ref (35)

tic criteria for psychoactive substance dependence and substance abuse are rather unwieldy and may not be applied with practicality and fairness to chronic pain patients (14). Alternative definitions of drug dependence and abuse were offered by the World Health Organization (36). However, these criteria make no allowances for chronic opioid therapy used to treat chronic non-malignant pain. Due to controversy surrounding the definition of abuse and dependency in chronic pain patients, several authors and organizations have offered alternative definitions and checklists (14, 27-45).

Table 1 illustrates diagnostic criteria for substance dependence as described in DSM-IV (35). The American Society of Addiction Medicine also developed separate recommendations for defining addiction in chronic pain patients treated with opioids as shown in Table 2 (37). Characteristics identified as central to diagnosing addiction in this population include the presence of adverse consequences associated with the use of opioids, loss of control over the use of opioids, and preoccupation with obtaining opioids despite the presence of adequate analgesia. Traditional indicators of addictive disease in chronic pain patients have typically been those described as drug seeking, such as obtaining medication from multiple providers, repeated episodes of prescription loss, and multiple requests for early refills (27, $34,38)$. Thus, dependency and addiction are more serious problems than abuse. In general, prescription abuse is defined as the misuse of prescribed medications by a patient in the clinical setting being treated by a physician for a recognized chronic pain or associated condition(s). Chabal et al (14) defined prescription opiate abuse as meeting three or more of the following criteria:

1. Overwhelming focus on opiate issues during pain clinic visits, persistent beyond the third clinic treatment session,

2. The pattern of early refills (3 or more) or escalating drug use in the absence of an acute change in the medical condition,

3. Multiple telephone calls or visits with requests for more opiates, early refills, or problems associated with the opiate prescription,

4. Prescription problems, including lost medications, spilled medications, or stolen medications, and

5. Opiates obtained from multiple providers, emergency rooms, or illegal sources.

Chabal et al (14) thought that the criteria had good reliability and can be applied during normal clinic interactions. They also reported that past opiate or alcohol abuse or psychological testing on clinic admission failed to predict who would become an opiate abuser. They felt that patients meeting three of the five criteria will subsequently require more intensive treatment or intervention.

Compton et al (27) also developed a screening questionnaire for addiction in patients with chronic pain and problematic substance use. In a small sample of patients $(n=52)$ referred from a multidisciplinary pain center for "problematic" medication use, responses to the screening questionnaires were compared between patients who met combined diagnostic criteria for a substance use disorder and those who did not, as assessed by a trained addiction medicine specialist. Responses of addicted patients were significantly different from those of nonaddicted patients on multiple screening items, with two groups easily differentiated by the total questionnaire score. They identified three key screening indicators as excellent predictors for the presence of addictive disease in this sample of chronic pain patients. The questionnaire consisted of 42 questions with evaluation of pain condition, opioid use patterns, social/family factors, family history, patient history of substance abuse, and psychiatric history. The three predictive indicators included patients' belief that he or she is addicted, increasing analgesic dose 
Table 2. American Society of Addiction medicine definitions related to the use of opioids in pain treatment

The Committee on Pain of the American Society of Addiction Medicine recognizes the following definitions as appropriate and clinically useful definitions and recommends their use when assessing the use of opioids in the context of pain treatment.

Physical dependence

Physical dependence on an opioid is a physiological state in which abrupt cessation of the opioid, or administration of an opioid antagonist, results in a withdrawal symptom. Physical dependency on opioids is an expected occurrence in all individuals in the presence of continuous use of opioids for therapeutic or for non-therapeutic purposes. It does not, in and of itself, imply addiction.

Tolerance

Tolerance is a form of neuroadaptation to the effects of chronically administered opioids (or other medications) which is indicated by the need for increasing or more frequent doses of the medication to achieve the initial effects of the drug. Tolerance may occur both to the analgesic effects of opioids and to unwanted side effects such as respiratory depression, sedation, or nausea. The occurrence of tolerance is variable in occurrence, but it does not, in and of itself, imply addiction.

\section{Addiction}

Addiction in the context of pain treatment with opioids is characterized by a persistent pattern of dysfunctional opioid use in that may involve any or all of the following:

- adverse consequences associated with the use of opioids

- loss of control over the use of opioids

- preoccupation with obtaining opioids despite the presence of adequate analgesia

Adapted from ref (37)

or frequency, and route of administration preference.

Atluri and Sudarshan (16) evaluated a preliminary screening tool in a case-controlled study of adult patients attending a community pain clinic, to estimate the risk of prescription opioid abuse among patients with chronic non-malignant pain. They studied 107 patients in an abuse group and 103 in a control group. Patients included in the abuse group were consecutive patients with chronic nonmalignant pain who failed a urine drug test. The control group was selected randomly. After evaluating multiple variables, they determined that six variables were significantly associated with abuse behavior. These included a focus on opioids, opioid overuse, other substance use, non-functional behavior, unclear etiology of pain, and exaggeration of pain. Manchikanti et al (7, 10-12) defined abuse in a clinical setting as obtaining controlled substances from other physicians or other identifiable sources, by inappropriate dose escalation, and/or violation of controlled substance agreements. Table 3 illustrates indicators developed by Chabal et al (14), Compton et al (27) and Atluri and Sudarshan (16).

However, these questionnaires have not been externally validated or are related to the psychiatric literature. Without standard or validated assessments, identification of drug abuse may be difficult. Such instruments may also be abused. Waddell et al (46) in 1980 developed a standardized assessment of behavioral responses to examination. Waddell et al (47) also identified non-physiological symptoms. These symptoms and signs were associated with other clinical measures of illness behavior and distress. However, only non-organic signs were standardized. Waddell et al $(46,47)$ attempted to integrate the non-organic signs into modern concepts of pain and illness behavior. However, they have become widely used and appeared under a variety of names such as Waddell signs, inappropriate signs, medically incongruent signs, non-physiological signs, and behavioral signs (48). Unfortunately, standardized non-organic signs and nonstandardized non-organic symptoms have been misinterpreted in clinical and medicolegal assessments (49). Main and Waddell (49) described a number of theoretical misunderstandings which may underlie the misuse of Waddell's signs. These included conscious versus unconscious origins of pain behavior, failure to understand fear-mediated responses, nature of recovery from injury and the development of chronic incapacity, co-existence with physical signs, objectivity, judgment, and bias. They noted that misuse and misinterpretation in clinical contexts occurred due to failure to adhere to the rec-

Table 3. Summary description of key criteria in the literature

\begin{tabular}{|l|l|l|}
\hline $\begin{array}{l}\text { Criteria by Atluri and } \\
\text { Sudarshan (16) }\end{array}$ & Criteria by Chabal et al (14) & Criteria by Compton et al (27) \\
\hline Focused on opioids & $\begin{array}{l}\text { Overwhelming focus on opiate issues during pain clinic visits, persistent } \\
\text { beyond the third clinic treatment session, }\end{array}$ & Belief of addiction by the patient \\
\hline Opioid overuse & $\begin{array}{l}\text { The pattern of early refills (3 or more) or escalating drug use in the } \\
\text { absence of an acute change in the medical condition }\end{array}$ & Increasing analgesic dose or frequency \\
\hline Other substance use & $\begin{array}{l}\text { Multiple telephone calls or visits with requests for more opiates, early } \\
\text { refills, or problems associated with the opiate prescription }\end{array}$ & Route of administration preference \\
\hline Non-functional & $\begin{array}{l}\text { Prescription problems, including lost medications, spilled medications, or } \\
\text { stolen medications }\end{array}$ & \\
\hline Exaggeration of pain & $\begin{array}{l}\text { Opiates obtained from multiple providers, emergency rooms, or illegal } \\
\text { sources }\end{array}$ \\
\hline Etiology of pain unclear & & \\
\hline
\end{tabular}


ommended cut-offs, with over-interpretation of isolated signs, mistaking the sign's test for a full psychological assessment, justification of refusal to offer adequate/ appropriate physical treatment, and inappropriate differential diagnoses. They also noted that misuse and misinterpretation in a medicolegal context occurred, with failure to recover from injury interpreted as deception. Thus, caution must be exercised in interpreting any test, measurement, assessment, or isolated features as indicative of drug abuse.

We have undertaken an external validation of the assessment tool developed by Atluri and Sudarshan (16). The assessment tool was modified to evaluate 12 sections with 27 items, and assessed in a prospective fashion in 500 consecutive patients, with 100 patients in the abuse group and 400 patients in the nonabuse group.

\section{Methods}

Based on a review of the literature, a set of guidelines for the assessment of drug abuse in patients with chronic pain in interventional pain management settings, developed by Atluri and Sudarshan (16), were utilized. These were modified to include 12 sections with 27 items. This assessment tool included the following sections: focus on opiates; nonphysiological behavior; substance abuse; nonfunctional status; excessive opiate needs; deception or lying to obtain controlled substances; current or prior intentional doctor shopping; current investigation or prior conviction for illicit drugs or opiates; altering prescriptions, current or prior use of illicit drugs and denial; needle tracks, skin abscesses, inflamed nares, and perforation of nasal septum; and psychological status which included somatization, depression and anxiety (Table 4 ). The interview and completion of the questionnaire were performed by the physician and a nurse trained in interviewing patients for interventional pain management.

To provide appropriate evidence for the utility of the assessment tool and determine how well it discriminates between chronic pain patients with and without drug abuse, the questionnaire was administered to 100 patients with a history of drug abuse and 400 patients without history of drug abuse consecutively in an interventional pain management setting. All patients were referred for interventional pain management with various
Table 4. Modified criteria studied in the assessment tool in this study

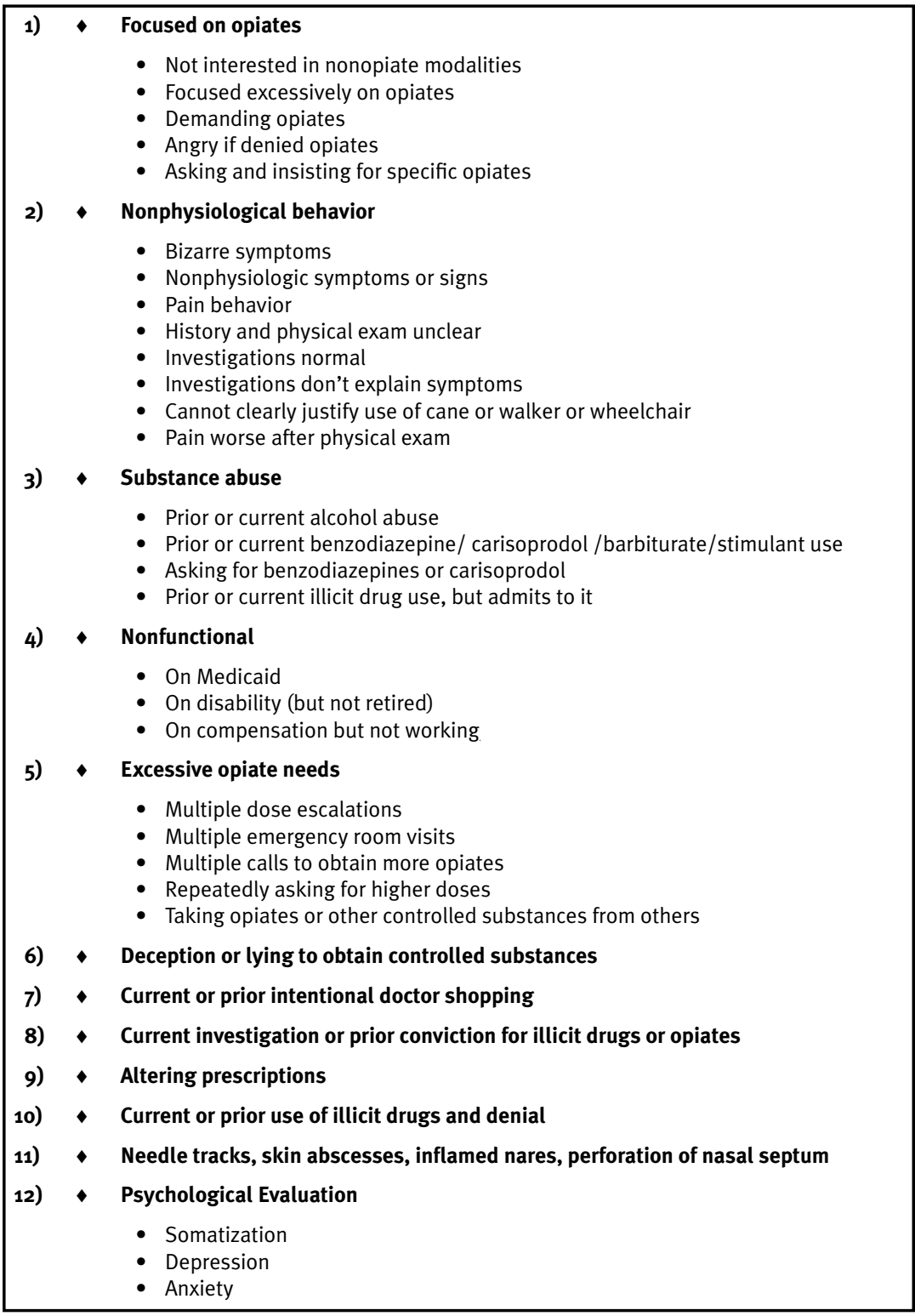

Table 5. Demographic characteristics

\begin{tabular}{|c|c|c|c|c|}
\hline \multirow{2}{*}{\multicolumn{2}{|c|}{ Number of Patients }} & Group I & Group II & \multirow{2}{*}{$P$ value } \\
\hline & & \multirow{2}{*}{$\frac{400}{42.3 \%(169)}$} & \multirow{2}{*}{$\frac{100}{35 \%(35)}$} & \\
\hline \multirow{2}{*}{ Gender } & Male & & & \multirow{2}{*}{0.211} \\
\hline & Female & $57.8 \%(231)$ & $65 \%(65)$ & \\
\hline Age & Mean \pm SD & $49 \cdot 5^{\star}+15 \cdot 3$ & $42.1+10.6$ & 0.000 \\
\hline Weight (lbs) & Mean \pm SD & $181.5+49.6$ & $172.4+45.8$ & 0.096 \\
\hline Height (inches) & Mean \pm SD & $66.9+3.8$ & $66.6+3.5$ & 0.581 \\
\hline Duration of pain & Mean \pm SD & $88.8+100.5$ & $98.8+100.5$ & 0.927 \\
\hline \multirow{2}{*}{$\begin{array}{l}\text { Onset of the } \\
\text { pain }\end{array}$} & Traumatic & $50.2 \%(201)$ & $67 \%(67)$ & \multirow{2}{*}{0.003} \\
\hline & Non-Traumatic & $49.8 \% *(199)$ & $33 \%(33)$ & \\
\hline \multicolumn{2}{|c|}{ History of previous spine surgery } & $29.5 \%(118)$ & $32 \%(32)$ & 0.627 \\
\hline
\end{tabular}

* Indicates significant difference 
types of problems, with a majority having chronic spinal pain. All patients were on controlled substances prior to admission to the interventional pain management practice. Patients were followed for a period of one year prior to completion of the assessment. The study design met institutional review board criteria.
Drug abuse was considered as the misuse of controlled substances in a clinical setting, including obtaining controlled substances from other physicians or other identifiable sources, dose escalations with inappropriate use, and/or violation of controlled substance agreement. Data were collected in a preprinted format
(Table 4). Statistical assessment used the Chi-square test, with odds ratio determination. $P$ values $<.001$ were considered significant.

\section{RESULTS}

A total of 500 patients were enrolled in this study, with 400 patients identified

Table 6. Analysis of multiple factors of the assessment tool studied

\begin{tabular}{|c|c|c|c|c|}
\hline & Group I (400) & Group II (100) & P Value & Odds Ratio \\
\hline 1. Focused on opiates & $8.5 \%(34)$ & $49.0 \%(49)$ & 0.000 & 10.34 \\
\hline i. Not interested in nonopiate modalities & $0.5 \%(2)$ & $4.0 \%(4)$ & 0.016 & 8.29 \\
\hline ii. Focused excessively on opiates & $5.3 \%(21)$ & $37.0 \%(37)$ & 0.000 & 10.60 \\
\hline iii. Demanding opiates & $1.5 \%(6)$ & $5.0 \%(5)$ & 0.048 & 3.46 \\
\hline iv. Angry if denied opiates & $1.3 \%(5)$ & $8.0 \%(8)$ & 0.001 & 6.87 \\
\hline v. Asking and insisting for specific opiates & $2.5 \%(10)$ & $20.0 \%(20)$ & 0.000 & 9.75 \\
\hline 2. Nonphysiological behavior & $69.0 \%(276)$ & $66.0 \%(66)$ & 0.631 & 0.87 \\
\hline i. Bizarre symptoms & $26.3 \%(105)$ & $39.0 \%(39)$ & 0.014 & 1.80 \\
\hline ii. Nonphysiologic symptoms or signs & $27.0 \%(108)$ & $27.0 \%(27)$ & 1.000 & 1.00 \\
\hline iii. Pain behavior & $37 \cdot 5 \%(150)$ & $54.0 \%(54)$ & 0.003 & 1.96 \\
\hline iv. History and physical exam unclear & $33.0 \%(132)$ & $11.0 \%(11)$ & 0.000 & 0.25 \\
\hline v. Investigations normal & $3.3 \%(13)$ & $2.0 \%(2)$ & 0.746 & 0.61 \\
\hline vi. Investigations don’t explain symptoms & $2.3 \%(9)$ & $2.0 \%(2)$ & 1.000 & 0.89 \\
\hline vii. Cannot clearly justify use of cane or walker or Wheelchair & $0.3 \%(1)$ & $0.0 \%(0)$ & 1.000 & 0.00 \\
\hline viii. Pain worse after physical exam & $1.0 \%(4)$ & $1.0 \%(1)$ & 1.000 & 1.00 \\
\hline 3. Substance abuse & $35.5 \%(142)$ & $64.0 \%(64)$ & 0.000 & 3.23 \\
\hline i. Prior or current alcohol abuse & $10.5 \%(42)$ & $10.0 \%(10)$ & 1.000 & 0.95 \\
\hline ii. Prior or current benzodiazepine/soma/barbiturate/stimulant use & $27.8 \%(111)$ & $54.0 \%(54)$ & 0.000 & 3.06 \\
\hline iii. Asking for benzodiazepines or soma & $0.3 \%(1)$ & $7.0 \%(7)$ & 0.000 & 30.03 \\
\hline iv. Prior or current illicit drug use, but admits to it & $2.8 \%(11)$ & $5.0 \%(5)$ & 0.335 & 1.86 \\
\hline 4. Nonfunctional & $44 \cdot 3 \%(177)$ & $76.0 \%(76)$ & 0.000 & 3.99 \\
\hline i. On Medicaid & $20.8 \%(83)$ & $48.0 \%(48)$ & 0.000 & 3.53 \\
\hline ii. On disability (but not retired) & $22.5 \%(90)$ & $30.0 \%(30)$ & 0.118 & 1.48 \\
\hline iii. On compensation but not working & $5.0 \%(20)$ & $9.0 \%(9)$ & 0.149 & 1.88 \\
\hline 5. Excessive opiate needs & $19.0 \%(76)$ & $96.0 \%(96)$ & 0.000 & 102.32 \\
\hline i. Multiple dose escalations & $0.3 \%(1)$ & $5.0 \%(5)$ & 0.001 & 21.00 \\
\hline ii. Multiple emergency room visits & $2.8 \%(11)$ & $7 \%(7)$ & 0.000 & 2.66 \\
\hline iii. Multiple calls to obtain more opiates & $7.8 \%(31)$ & $47.0 \%(47)$ & 0.000 & 10.56 \\
\hline iv. Repeatedly asking for higher doses & $0.8 \%(3)$ & $13.0 \%(13)$ & 0.000 & 19.77 \\
\hline v. Taking opiates or other controlled substances from others & $9.3 \%(37)$ & $91.0 \%(91)$ & 0.000 & 99.20 \\
\hline 6. Deception or lying to obtain controlled substance & $2.8 \%(11)$ & $84.0 \%(84)$ & 0.000 & 185.66 \\
\hline 7. Current or prior intentional doctor shopping & $3.0 \%(12)$ & $77.0 \%(77)$ & 0.000 & 108.25 \\
\hline 8. Current investigation or prior conviction for illicit drugs or opiates & $0.5 \%(2)$ & $14.0 \%(14)$ & 0.000 & 32.4 \\
\hline 9. Altering prescriptions & $0.3 \%(1)$ & $1.0 \% 1)$ & 0.360 & 4.03 \\
\hline 10. Current or prior use of illicit drugs and denial & $0 \%$ & $7.0 \%(7)$ & 0.000 & NA \\
\hline 11. Needle tracks, skin abscesses, inflamed nares, perforation of nasal septum & $0 \%$ & $0 \%$ & NA & NA \\
\hline \multicolumn{5}{|l|}{ 12. Psychological Status } \\
\hline i. Somatization & $31.9 \%(110)$ & $39.7 \%(31)$ & 0.186 & 1.18 \\
\hline ii. Depression & $55.4 \%(191)$ & $41.0 \%(32)$ & 0.022 & 0.51 \\
\hline iii. Anxiety & $54.2 \%(187)$ & $47.4 \%(37)$ & 0.316 & 0.67 \\
\hline
\end{tabular}


as the non-abuse group (Group I) and 100 patients identified as the abuse group (Group II). Data were available for at least 10 of 12 sections for all patients.

\section{Demographics}

As shown in Table 5, there were no differences noted with regards to gender distribution, height, weight, duration of pain, and history of previous spine surgery. Significant differences were noted with age and mode of onset of pain.

\section{Factor Analysis}

Table 6 shows the responses 12 major headings and the individual items for both groups. The responses showed a positive correlation with drug abuse in 8 of the 12 sections. Positive correlations were established for behavior showing a focus on opiates, history of sub- stance abuse, non-functional status, excessive opiate needs, deception or lying to obtain controlled substances, current or prior intentional doctor shopping, current investigation or prior conviction for illicit drugs or opiates, and current or prior use of illicit drugs. None of the patients had needle tracks, skin abscesses, inflamed nares, or perforation of the nasal septum. No correlation was noted with an unclear history or physical examination. No correlation was noted overall with non-physiological behavior, alteration of prescriptions, and psychological status. Thus, of the 12 sections, 8 showed significant difference. Items with $P$ values of 0.001 were identified as significant.

\section{Positive Correlation and Odds Ratio}

Odds ratios for each item are shown in Table 7. An odds ratio of 100 or high-
Table 7. Positive correlation of various items with odds ratio

\begin{tabular}{|l|l|l|l|l|}
\hline & \multicolumn{1}{|c|}{$\begin{array}{c}\text { Group I } \\
(400)\end{array}$} & $\begin{array}{c}\text { Group II } \\
(100)\end{array}$ & P value & Odds Ratio \\
\hline 1. Focused on opiates (Section 1) & $8.5 \%(34)$ & $49.0 \%(49)$ & 0.000 & 10.34 \\
\hline 2. Substance abuse (Section 3) & $35.5 \%(142)$ & $64.0 \%(64)$ & 0.000 & 3.23 \\
\hline 3. Nonfunctional (Section 4) & $44.3 \%(177)$ & $76.0 \%(76)$ & 0.000 & 3.99 \\
\hline 4. Excessive opiate needs (Section 5) & $19.0 \%(76)$ & $96.0 \%(96)$ & 0.000 & 102.32 \\
\hline $\begin{array}{l}\text { 5. Deception or lying to obtain } \\
\text { controlled substance (Section 6) }\end{array}$ & $2.8 \%(11)$ & $84.0 \%(84)$ & 0.000 & 185.66 \\
\hline $\begin{array}{l}\text { 6. Current or prior intentional doctor } \\
\text { shopping (Section 7) }\end{array}$ & $3.0 \%(12)$ & $77.0 \%(77)$ & 0.000 & 108.25 \\
\hline $\begin{array}{l}\text { 7. Current investigation or prior } \\
\text { conviction for illicit drugs or } \\
\text { opiates (Section 8) }\end{array}$ & $0.5 \%(2)$ & $14.0 \%(14)$ & 0.000 & 32.4 \\
\hline $\begin{array}{c}\text { 8. Current or prior use of illicit drugs } \\
\text { and denial (Section 10) }\end{array}$ & $0 \%(0)$ & $7.0 \%(7)$ & 0.000 & NA \\
\hline
\end{tabular}

Table 8. Classification results from discriminant analysis using 8 items

\begin{tabular}{|l|l|l|l|}
\hline \multicolumn{2}{|c|}{} & Predicted Group \\
\cline { 3 - 4 } \multicolumn{2}{c|}{} & Group I & Group II \\
\hline \multirow{2}{*}{ Original Group } & Group II & $13 \%(13)$ & $\mathbf{8 7 \% ( 8 0 )}$ \\
\cline { 2 - 4 } & Group I & $\mathbf{9 7 \% ( 3 8 9 )}$ & $3 \%(11)$ \\
\hline
\end{tabular}

$95.2 \%$ of original grouped cases correctly classified

Table 9. Total score of section 1 , section 4 , section 5 , section 6 , section 7 , section 8 , and section 10

\begin{tabular}{|c|c|c|c|}
\hline & \multicolumn{2}{|c|}{ Original Group } \\
\hline & & Group I & Group II \\
\hline \multirow{2}{*}{ Total Score } & $\begin{array}{c}<3 \\
\text { (Non-abuse) }\end{array}$ & $94 \%(373)$ & $6 \%(6)$ \\
\hline & $\begin{array}{r}\geq 3 \\
\text { (Abuse) }\end{array}$ & $6 \%(23)$ & $94 \%(94)$ \\
\hline
\end{tabular}

$93.6 \%$ of original grouped cases correctly classified er was present for 3 items, 32.4 for one item, 10.3 for one item, 3.23 for one item. As shown in Table 8, discriminant analysis was performed using the 8 positive items illustrated in Table 7 . This analysis showed significant correlation with groups, with accurate classification into Group I and Group II in $95.2 \%$ of cases. There was a positive predictive value in $97 \%$ of patients in Group I and $87 \%$ of patients in Group II.

To identify those items from the assessment tool that best classified into drug abuse or non drug abuse patients, discriminant function analyses were performed for the 8 variables. The items were selected in a forward stepwise method using Wiliks Lambda's method ( $\mathrm{P}$ to enter set at 0.05 and P-to-remove set at 0.10). Seven of the above 8 sections (section 1 , section 4 , section 5 , section 6 , section 7 , section 8 , and section 10) were identified as those best able to predict the drugabuse or normal patients in the study subjects, correctly classifying $95.2 \%$ of patients (Table 8).

To simplify the above results, we also computed total scores for section 1 , section 4 , section 5 , section 6 , section 7 , section 8 , and section 10 . If the total was more than or equal to 3 , we classified patients as belonging to Group II. With a score of less than 3 , we classified patients as belonging to Group I ( $\mathrm{Ta}$ ble 9). Using the screening tool, $93.6 \%$ of the original groups were correctly identified as abuse or non-abuse. The correlation was $94 \%$ for both groups. This provided a positive predictive value of $94 \%$

\section{Predictive Indicators}

To simplify the assessment tool, we further assessed the 3 items with odds ratios of 100 or higher (Table 7): excessive opiate needs, deception or lying to obtain controlled substances, and doctor shopping. Based on this analysis, patients with less than 2 positive sections were classified into the non-abuse group and those with 2 or more were classified into the abuse group. There was a $97 \%$ correlation in Group I, a 90\% correlation in Group II, and an overall accurate classification in $95.2 \%$ of the patients. Evaluation of 3 of the 8 sections (with odds ratios higher than 100) were able to predict abuse and non-abuse in approximately $95 \%$ of cases. 
Table 10. Total score of section 5, section 6, and section 7 (Based upon odds ratio $>100$ )

\begin{tabular}{|l|c|l|l|}
\hline \multicolumn{3}{|c|}{} & \multicolumn{2}{|l|}{ Original Group } \\
\cline { 3 - 4 } \multicolumn{2}{|c|}{} & Group I & Group II \\
\hline \multirow{3}{*}{ Total Score } & $\begin{array}{c}<2 \\
\text { (Non-abuse) }\end{array}$ & $97 \%(386)$ & $10 \%(10)$ \\
\cline { 2 - 4 } & $\begin{array}{r}\geq 2 \\
\text { (Abuse) }\end{array}$ & $3 \%(14)$ & $90 \%(90)$ \\
\hline
\end{tabular}

\section{Assessment Instrument}

Based on this evaluation, an assessment instrument was identified with 3 criteria as follows:

\section{Excessive opiate needs}

i. Multiple dose escalations

ii. Multiple emergency room visits iii.Multiple calls to obtain more opiates iv. Repeatedly asking for higher doses

v. Taking opiates or other controlled substances from others

2. Deception or lying to obtain controlled substance

3. Current or prior intentional doctor shopping

\section{DISCUSSION}

This prospective, controlled study validated 8 of 12 criteria as described by Atluri and Sudarshan (16). Further analysis and stratification yielded $95 \%$ accuracy in identifying abuse and non-abuse groups, using 3 sections with odds ratios greater than 100 . This assessment tool reduced the number of items to be evaluated, thus increasing clinical feasibility. This analysis furthered the development of a standardized objective assessment tool to screen for drug abuse in patients with chronic pain seeking interventional pain management and controlled substances for pain.

Data from this study supported some of the commonly held assumptions about the predictive value of "drug-seeking" or "drug-abuse" behaviors for controlled substance abuse in chronic pain patients in interventional pain management settings. Results of this evaluation are consistent with previous reports. Even though high statistical significance and odds ratios of over 100 were utilized, $3 \%$ of the patients who were not drug abusers were incorrectly classified into Group II (drug abusers). Thus, the assessment tool should be utilized appropriately in its entirety without temptation to use individual items. It is not recommended that this tool be used in medicolegal situations. Even in clinical settings, this assessment should not be utilized as the sole determinant until further studies are performed confirming the value and validity of these criteria. In its current form as described in this evaluation, subjects who met 2 or more criteria consistently ( $90 \%$ of the time) showed controlled substance abuse.

This study confirmed the results of Atluri and Sudarshan (16) supporting 4 of 6 criteria. We were unable to confirm 2 of 3 criteria described by Compton et al (27): patient's belief of addiction and route of administration preference. However, these two items were not systematically evaluated in our study because almost all patients in this setting believed that they were not addicted and patients never expressed a preference for parenteral over oral administration. All the criteria (6 of 6) described by Chabal et al (14) were confirmed in this study.

This study may be criticized for our definition of drug abuse. One can hypothesize that patients identified as drug abusers in this study were not abusers, but rather suffered from pseudoaddiction (39). However, the definition of pseudoaddiction was based on a patient with cancer pain, with well-defined pathology, who was undertreated with parenteral opioids prescribed on an as needed basis. In contrast, the patients involved in the present study differed from the patient described by Weissman and Haddox (39). None of our patients were suffering with malignancy, pain of less than six months' duration, or psychogenic pain. All were considered to have a structural basis for their pain and were stable medically for at least one year.

Substance abuse per se, which included previous drugs and alcohol use, did not predict later opiate abuse. Some surveys have reported abuse of alcohol to be as high as 49\% (5052). Our results showed that prior or current alcohol abuse was similar in abuse and non-abuse groups. Further, prior or current illicit drug use, when admitted by the patient, also was similar in both groups and was not predictive of substance abuse. This was similar to the results of Chabal et al (14) who suggested that a past history of drug or alcohol abuse, pain levels, or depressive symptoms should not be a contraindication to opiate treatment for chronic pain. However, our study showed prior or current benzodiazepine, carisoprodal, barbiturate, or stimulant use, as well as requests for benzodiazepines or carisoprodal to be significant predictive factors of substance abuse.

In summary, the assessment tool developed in this study appears to be simple and reliable, and applicable to patients in interventional pain management settings. It is not intended to be used in isolation. Further, controlled studies validating the concept are required prior to wide application of this assessment tool.

\section{Conclusion}

This controlled, prospective study followed 500 patients for one year. 100 patients had a history of drug abuse and 400 patients did not have a history of drug abuse. 8 of 12 factors were identified as predictive of drug abuse. A subset of 3 factors (excessive opiate needs, deception or lying and doctor shopping) were particularly useful in identifying drug abuse, with $90 \%$ accuracy when 2 of the 3 factors were positive.

\section{ACKNOWLEDGMENTS}

We thank Drs. Atluri and Sudarshan for providing us with their instrument. We also wish to thank Tonie Hatton, Lorie Caldwell and Marla Neihoff, for their assistance in preparation of this manuscript. 


Author Affiliation
Laxmaiah Manchikanti, MD
Medical Director
Pain Management Center of Paducah
2831 Lone Oak Road
Paducah, Kentucky-42003
E-mail: drm@apex.net
Vijay Singh, MD
Medical Director
Pain Diagnostics Associates
1601 Roosevelt Road
Niagara, Wisconsin-54151
E-mail: vijsin@netscap.net
Kim S. Damron, RN
Clinical Coordinator
Ambulatory Surgery Center
2831 Lone Oak Road
Paducah, Kentucky-42003
E-mail: kim @thepainmd.com
Carla D. Beyer, RN, BSN
Clinical Coordinator
Ambulatory Surgery Center
2831 Lone Oak Road
Paducah, Kentucky-42003
E-mail: carla@thepainmd.com
Vidyasagar Pampati, MSc
Statistician
Pain Management Center of Paducah
2831 Lone Oak Road
Paducah, Kentucky-42003
E-mail sagar@thepainmd.com

\section{REFERENCES}

1. Epidemiologic Trends in Drug Abuse Advance Report. Community Epidemiology Work Group. National Institutes of Health. National Institute on Drug Abuse. CEWG Publications, Rockville, Maryland, June 2001.

2. The D.A.W.N. Report. Office of Applied Studies, Substance Abuse and Mental Health Services Administration (SAMHSA); Jan 2003.

3. Simoni-Wastila L, Tompkins C. Balancing diversion control and medical necessity: The case of prescription drugs with abuse potential. Substance Use \& Misuse 2001; 36:1275-1296.

4. Batten HL, Prottas JM, Horgan CM et al. Drug Services Research Survey. Phase II Final Report. Submitted to the National Institute on Drug Abuse. Institute for Health Policy, Brandeis University, Waltham, MA February 12, 1993.

5. 2001 National Household Survey on Drug Abuse (NHSDA). DHHS Publication No. (SMA) 02-3758. Rockville, MD: Department of Health and Human Services; Substance Abuse and Mental Health Services Administration, 2002.

6. The NHSDA Report. Nonmedical Use of Prescription-Type Drugs among Youths and Young Adults. Office of Applied Studies, Substance Abuse and Mental Health Services Administration (SAMHSA), Jan 2003.

7. Manchikanti L, Pampati V, Damron K et al. Prevalence of illicit drug use in patients without controlled substance abuse in interventional pain management. Pain Physician 2003; 6:173-178.

8. Lewin ICF. Analysis of Prescription Monitoring Programs. Prepared for HoffmanLaRoche by Lewin ICF. Washington DC, April 26, 1991.

9. Fishbain DA, Rosomoff HL, Rosomoff RS Drug abuse, dependence, and addiction in chronic pain patients. Clin J Pain 1992; 8: 77-85.

10. Manchikanti L, Pampati V, Damron K et al. Prevalence of opioid abuse in interventional pain medicine practice settings: A randomized clinical evaluation. Pain Physician 2001; 4:358-365.

11. Manchikanti L, Pampati V, Damron K. Prevalence of prescription drug abuse and dependency in patients with chronic pain in western Kentucky. J KY Med Assoc 2003; in press.

12. Manchikanti L, Beyer C, Damron K et al. A comparative evaluation of illicit drug use in patients with or without controlled substance abuse in interventional pain management. Pain Physician 2003; 6:281286.

13. Polatin PB, Kinney RK, Gatchel RJ et al. Psychiatric illness and chronic low back pain: The mind and the spine - which goes first? Spine 1993; 18:66-71.

14. Chabal C, Erjavec MK, Jacobson L et al. Prescription opiate abuse in chronic pain patients: Clinical criteria, incidence, and predictors. Clin J Pain 1997; 13:150-155.

15. Atluri S, Boswell M, Hansen $\mathrm{H}$ et al. Guidelines for the use of controlled substances in the management of chronic pain. Pain Physician 2003; 6:233-257.

16. Atluri S, Sudarshan G. A screening tool to determine the risk of prescription opioid abuse among patients with chronic nonmalignant pain. Pain Physician 2002; 5: 447-448.

17. Manchikanti L, Brown K, Singh V. National All Schedules Prescription Electronic Reporting Act NASPER: Balancing substance abuse and medical necessity in interventional pain management. Pain Physician 2002; 5:294-319.

18. Anthony JC. Drug use and dependence outside medical settings: Recent epidemiological evidence. TEN 2000; 2:54-58.

19. Joranson DE, Ryan KM, Gilson AM et al. Trends in medical use and abuse of opioid analgesics. JAMA 2000; 283:1710-1714.

20. Drug Enforcement Administration, National Alliance for Model State Drug Laws. Diversion and abuse of prescription drugs: A closer look at state prescription monitoring programs. Washington, DC: Drug Enforcement Administration, 2000. http://www.deadiversion.usdoj.g ov/pubs/program/prescription_monitor/ index.html).

21. Kentucky Drug Threat Assessment. National Drug Intelligence Center and Kentucky State Police. Product No. 2002SO382 KY-001, July 2002.

22. The KASPER Program. The KY Cabinet for Health Services. Department for Public Health. dphdrugcontrol@mail.state.ky.u

23. Houck LK. The Drug Enforcement Ad ministration, Controlled Substances and Pain Management. http://www.deadive rsion.usdoj.gov/pubs/nwslttr/spec2001/ page10.htm

24. Robertson JR, treasure W. Benzodiazepine abuse. Nature and extent of the problem. CNS Drugs 1996; 5:137-146.

25. Gelkopf M, Bleich A, Hayward R et al. Characteristics of benzodiazepine abuse in methadone maintenance treatment patients: A 1-year prospective study in an Israeli clinic. Drug Alcohol Depend 1999; 55:63-68.

26. American Medical Association. Curtailing prescription drug abuse while preserving therapeutic use: American Medical Association recommendations for drug control policy. In Wilford BB (ed). Balancing the Response to Prescription Drug Abuse. American Medical Association, Chicago, 1990, pp 273-298.

27. Compton P, Darakjian J, Miotto K. Screening for addiction in patients with chronic pain and "problematic" substance use: Evaluation of a pilot assessment tool. J Pain Symptom Manage 1998; 16:355-363.

28. Dunbar SA, Katz NP. Chronic opioid therapy for nonmalignant pain in patients with a history of substance abuse: Report of 20 cases. J Pain Symptom Manage 1996; 11: 163-171.

29. Coambs R, Jarry JL, Santhiapillai AC et al. The SISAP: A new screening instrument for identifying potential opioid abusers in the management of chronic nonmalignant pain within general medical practice. Pain Res Manage 1996; 1:155-162.

30. Passik SD, Whitcomb L, Dodd S et al. Pain outcomes in long-term treatment with opioids: Preliminary results with a newly developed physician checklist. The fourth conference on pain management and chemical dependency. Washington, DC; 2000.

31. Fishman SM, Wilsey B, Yang J et al. Adherence monitoring and drug surveillance in chronic opioid therapy. J Pain Symptom Manage 2000; 20:293-307.

32. Sees KL, Clark W. Opioid use in the treatment of chronic pain: Assessment of addiction. J Pain Symptom Manage 1993; 8: 257-264.

33. Miotto K, Compton P, Ling W et al. Diagnosing addictive disease in chronic pain patients. Psychosomatics 1996; 37:223235.

34. Pancratz L, Hickman DH, Toth S. The identification and management of drug-seek 
ing behavior in a medical center. Drug Alcohol Depend 1989; 24:115-118.

35. American Psychiatric Association. Diagnostic and statistical manual of mental disorders, $4^{\text {th }}$ ed. Washington, DC: American Psychiatric Association, 1994.

36. Kleber $\mathrm{H}$. The nosology of abuse and dependence. J Psychiatr Res 1990; 24:5764 .

37. Graham AW, Schultz TK, Mayo-Smith MF et al (eds). Principles of Addiction Medicine, Third Edition. American Society of Addiction Medicine (ASAM) Publications, Chevy Chase, 2003.

38. Portenoy RK. Opioid therapy for chronic non-malignant pain: Current status. In Fields HL, Liebeskind JC (eds). Progress in Pain Research and Management, Vol. 1. IASP Press, Seattle, 1994:247-287.

39. Weissman DE, Haddox JD. Opioid pseudoaddiction: An iatrogenic syndrome. Pain 1989; 36:363-366.

40. Fishbain DA. Report on the prevalence of drug/alcohol abuse and dependence in chronic pain patients (CPPs). Subst Use Misuse 1996; 31:945-946.

41. Haller DL, Butler S. Use and abuse of prescription and recreational drugs by chronic pain patients. In Harris LS (ed). Problems of drug dependence, 1990. Washington DC: GPO, 1991: 456-457.

42. Chabal C, Jacobson L, Chaney EF et al. Narcotics for chronic pain: Yes or no? A useless dichotomy. Am Pain Soc J 1992; 1 : 276-281.

43. Chabal C, Jacobson L, Chaney EF et al. The psychosocial impact of opioid treatment. Am Pain Soc J 1992; 1:289-291.

44. Chabal C, Jacobson L, Mariano A et al. Chronic nonmalignant pain: A syndrome not a diagnosis. Am Pain Soc J 1994; 3: 138-139.

45. Portenoy R. Chronic opioid therapy for nonmalignant pain: From models to practice. Am Pain Soc J 1992; 3:285-288.

46. Waddell G, McCulloch JA, Kummel E et al. Non-organic physical signs in low back pain. Spine 1980; 5:117-125.
47. Waddell G, Main CJ, Morris EW et al. Chronic low back pain, psychological distress, and illness behavior. Spine 1984; 9: 209-213.

48. Main CJ, Waddell G. Behavior response to examination. A reappraisal of the interpretation of "nonorganic signs." Spine 1998; 23:2367-2371.

49. Waddell G, Bircher M, Finlayson D et al. Symptoms and signs: Physical disease or illness behavior? BM/ 1984; 289:739-741.

50. Taub A. Opioid analgescis in the treatment of chronic intractable pain of non-neoplastic origin. In Kitahata LM, Collins D (eds). Narcotic analgesics in anesthesiology. Williams and Wilkins, Baltimore, 1982.

51. Magruder-Habib K, Saltz EE, Barron PM. Age related patterns of alcoholism among beterands in ambulatory care. Hospital and Community Psychiatry 1986; 37:12511255 .

52. Williams M. Alcohol and the elderly: An overview. Alcohol Health Res World 1984; 8:3-12. 
